\title{
Huge Nulliparous Prolapse with Cervical Dystocia
}

\author{
Shikha Seth', Arun Nagrath ', Dinesh K. Singh'2, Rajni Deoghary ' \\ Dept. Obs/Gyn', Dept. of Paediatrics ${ }^{2}$ \\ U.P Rural Institute of Medical Sciences \& Research Saifai, Etawah.
}

\begin{abstract}
Prolapse is usually seen in multipara cases after the difficult delivery. Normally during pregnancy, prolapsed uterine cervix usually gets pulled inside due to growth of uterus abdominally. A nulliparous case complaining of something coming out first time, during pregnancy and ultimately landing into cervical dystocia is an even rarer entity.

Cutting of the cervical rim to facilitate delivery in cases of cervical dystocia also termed as hystero-stomatomy or "Duhrssen's incision" after the gynaecologist, Alfred Duhrssen who described it. Faulty dilatation of cervix is usual in prolapse cases and had been treated by a variety of methods out of which Duhrsen's incision is said to be the best.

A case of nulliparous full term pregnancy, admitted with obstructed labour caused by cervical dystocia by prolapsed cervix, who finally benefited with small Duhrssen's incision is being described herewith.
\end{abstract}

Key words: Nulliparous prolapse, Cervical dystocia, Duhrssen's incision.

\section{Introduction}

Utero-cervical prolapse complicating pregnancy is rare with an estimated incidence of 1 per 10,000 $-15,000$ deliveries ${ }^{1}$. Prolapsed cervix poses problem in conception and the reported complications that result during pregnancy are minor cervical desiccation and ulceration, spontaneous abortion, preterm labour, premature delivery, maternal sepsis, urinary retention, and cervical dystocia ${ }^{2,3}$. Predisposing factors for this condition is weakness of supporting structures which can be congenital, or develop due to injury, repeated child births or after menopause. It is usually seen in multipara cases after the difficult delivery. Normally during pregnancy, prolapsed cervix usually gets pulled inside due to growth of uterus abdominally. A nulliparous case complaining of something coming out first time, during pregnancy and ultimately landing into cervical dystocia is an even rarer entity and is being presented here with a successful fetal and maternal outcome.

\section{Case}

A 21 years old full term primigravida, with labour pains and complaint of something coming out per-vaginum since last 5 months was admitted on 07/07/10 at U.P. RIMS and R Saifai. The findings of general physical examination were normal except for mild anaemia. On per abdomen examination, uterus was 32 weeks by fundal height, fetal parts were palpable and uterine contractions were of good intensity. Fetal heart sound was regular 126 beats / min. Local examination revealed about $15 \mathrm{~cm}$ long cervix protruding outside the introitus, $6-7 \mathrm{~cm}$ dilated with fetal scalp visible (fig 1).

Delivery was facilitated by giving injection epidosin followed by Duhrssen's incision at 7 O'clock position resulting in a healthy female baby of weight $2.6 \mathrm{Kg}$ with a large, caput succedaneum due to prolonged cervical dystocia. Placenta expelled spontaneously. Immediately after delivery, cervix was lying 4 inches

Correspondence

Dr. Shikha Seth (MD)

Assistant Professor

Dept. Obs/Gyn

U.P. R.I.M.S. \& R. Saifai, Etawah, Uttar Pradesh,

PIN: 206301.

Phone: 09411850238

E-mail :drseth_shikha@yahoo.com,fax:05688-276509 


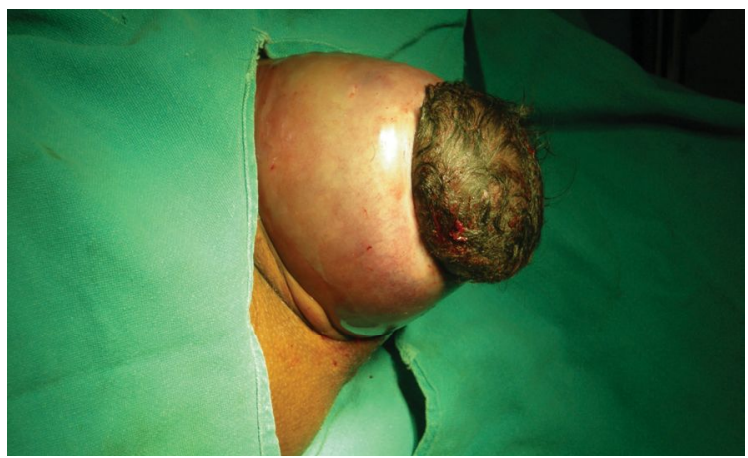

Fig 1. Huge nulliparous prolapse in second stage of labour with head being obstructed by tight cervical rim (cervical dystocia) leading to big caput succedaneum formation.

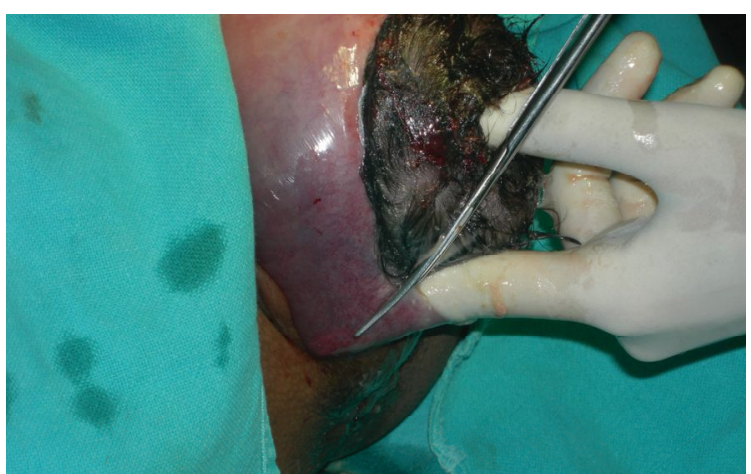

Fig 2. Cervical Rim being cut at $7 \mathrm{O}^{\prime}$ clock position (Duhrssen's incision) by scissors under the guidance of index finger to avoid injury to fetal head.

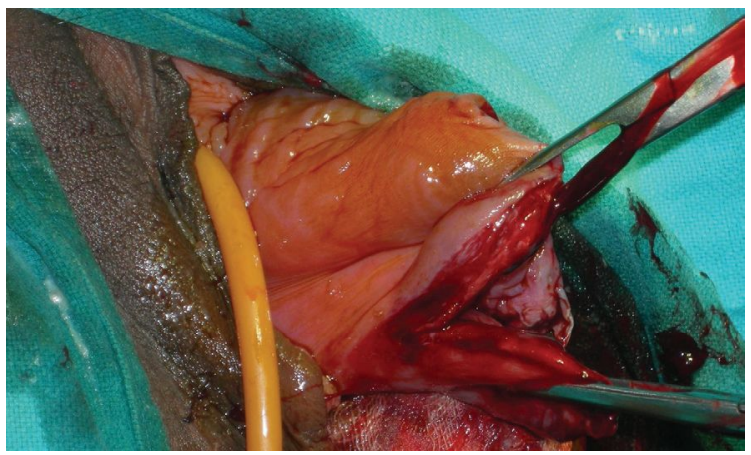

Fig 3. Cervical tear after delivery of the fetus. Note the cervix lying completely out of the introitus even after delivery.

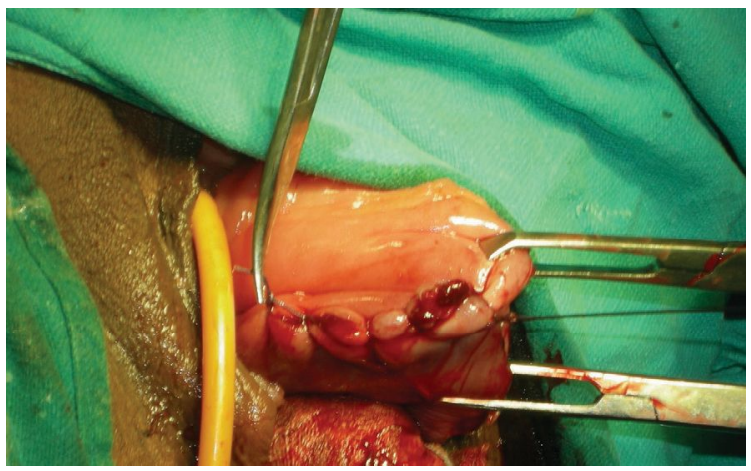

Fig 4. Duhrssen's incision completely stitched. outside the vulva. The cut edges of the incision were grasped with tissue holding forceps and stitched by continuous sutures of vicryl. She was discharged after 72 hours of hospital stay without any complications.

\section{Discussion}

Cutting of the cervical rim to facilitate delivery in cases of cervical dystocia also termed as hysterostomatomy or "Duhrssen's incision" named after the Gynaecologist, Alfred Duhrssen who first described it was used in our case to overcome obstruction. Faulty dilatation of cervix has been treated by a variety of ineffective or hazardous methods since past as, hot enemas, electrical stimulation of nipples, bags, bougies, manual dilatation and use of special instruments for stretching the cervix apart from cervical incision. Procedures waned in popularity as the indications for and safety of Caesarean section increased. Duhrssen had advocated safety of this incision in cases of primigravidas when entire-vaginal portion of cervix had already dilated, as well as the internal os and problem was only restricted to the portio-vaginalis or external os which remains rigid and unyielding, in preference over the caesarean section ${ }^{4}$.

Number and site of incisions have changed since original description and for safety point of view two incisions at 5 and 7 O'clock position is said to be the best thus avoiding haemorrhage from the descending cervical vessels and preventing the injury to bladder in case, the incision extends during delivery of the baby. Deferring this incision carries the inherent risk of bucket handle tear or in severe cases an annular detachment of the cervix.

\section{References}

1. Daskalakis G, Lymberopoulos D, Anastasakis E et al. Uterine prolapse complicationg pregnancy. Arch Gynecol Obstet 2007; 276: 391-392.

2. Sawyer D, Frey K. Cervical prolapses during prolaso. J Am Board Fam Pract 1999; 13: 216218.

3. Yogev Y, Horowitz ER, Ben-Haroush A et al. Uterine cervical elongation and prolapse during pregnancy: an old unsolved problem. Clin Exp Obstet Gynecol 2003; 30: 183-85.

4. Duhrssen A. Ueber den Werth der tiefen Cervix and Scheiden-Damm Einschnitte in der Geburshulfe. Arch. F. Gynak, 1890; 37: 27 - 66, (Abstracted in central bl.f. Gynak. 14: 548-549, 1890)

5. Bhatla N. Pelvic organ prolapse. In: Jeff Coates Principles of Gynecology $5^{\text {th }}$ edition. London, Arnold Publisher. 2001; pp270 -71 